\title{
LA INVENCIÓN DE LENGUAS EN LA FICCIÓN LITERARIA
}

\author{
Carmen Galán Rodríguez \\ Universidad de Extremadura \\ cgalan@unex.es
}

\begin{abstract}
Resumen
Este trabajo analiza algunos relatos de viajes extraordinarios de los siglos XVII y XVIII cuyo objetivo era reconstruir la primitiva lengua adámica que se hablaba en toda la tierra antes de la maldición bíblica de Babel. Dicha lengua, en virtud de su relación especular con el mundo, era el vehículo más idóneo del conocimiento porque sus significados coincidían con el referente en un isomorfismo absoluto y lo representaban de manera perfecta. En el siglo XVIII se abandonará progresivamente la utopía de la lengua adámica, al tiempo que se afirmará la riqueza de la multiplicidad de lenguas. A finales de este siglo, tras la consolidación del método comparativo, el viejo sueño de la imago mundi desaparecerá definitivamente dejando paso a la construcción de lenguas con finalidad práctica, las lenguas a posteriori, que no partirán ya de la naturaleza de las cosas (como pretendían las lenguas utópicas del XVII), sino de la realidad lingüística que conforman las lenguas históricas.

PALABRAS CLAVE: Lenguas utópicas, lenguas filosóficas.
\end{abstract}

\begin{abstract}
This article analyses some seventeenthand eighteenth-century tales of extraordinary voyages, which aimed to reconstruct the primitive language of Adam that was spoken all over the world before the biblical curse of Babel. This language, as a mirror image of the world, was the ideal vehicle of knowledge because its signifiers coincided with the referent in absolute isomorphism and represented it perfectly. In the eighteenth, the utopia of a language of Adam was gradually abandoned, being replaced by an awareness of the wealth of variation among the languages. At the end of this century, after the consolidation of comparative methodology, the ancient utopian dream of the imago mundi disappeared completely, giving way to the construction of languages whose purpose was practical: the $a$ posteriori languages, which now did not take their shape from the nature of things (the aim of utopian languages), but from the linguistic reality of the historical languages.
\end{abstract}

KEY WORDS: Utopic languages, philosophical languages.

\section{El sueño de la lengua perfecta: la lingua adamica}

La historia de las ideas lingüísticas se ha desarrollado durante siglos acompañada por el sueño de la lengua perfecta. Y en este viaje de ficción, especialmente entre los siglos XVII y XVIII, las utopías lingüísticas han demostrado ser el lugar más idóneo para favorecer el reencuentro entre la ciencia y el mito gracias a la 
confluencia de tres fuerzas dispares: la impronta teológico-mítica de la Biblia (que inspirará la búsqueda de la primitiva lengua del Paraíso en lugares exóticos, o propiciará su reconstrucción artificial); la pretensión de los filósofos, tanto racionalistas como empiristas, de depurar el lenguaje para convertirlo en vehículo de expresión unívoca; y el descubrimiento de la lengua china, especialmente la fantasiosa hipótesis de que sus caracteres ideográficos representaban el mundo en una perfecta relación isomórfica.

Todas las civilizaciones, en tanto que constructos mitopoyéticos, tienen un mito propio para explicar el origen del lenguaje y su capacidad creadora de mundos. En nuestra civilización judeo-cristiana la referencia obligada es la Biblia, especialmente cinco episodios repartidos entre el Antiguo y Nuevo Testamento. Dichos textos configuran un corpus mítico que marcará de una manera determinante la evolución de las ideas linguísticas y gran parte de la literatura utópica (incluyendo algunas de las obras de ciencia ficción del siglo XX) que se desarrollará a partir de la publicación en 1516 de la Utopía de Tomás Moro.

El primero de los textos (Génesis, 2: 19) narra el don divino del lenguaje del que se servirá Adán para aprehender el universo, porque es preciso que cada cosa tenga un nombre para existir. Esta primigenia lingua adamica, perfecta en tanto que don divino, es un reflejo exacto de la esencia de las cosas (una imago mundi) y la garantía de la unidad de la especie humana: "Toda la tierra tenía una misma lengua y usaba las mismas palabras" (Génesis, 11: 1). Si bien en la historia de las ideas lingüísticas el carácter divino del origen del lenguaje se discutirá profusamente hasta terminar por prohibirse en 1866, la búsqueda de la lengua perfecta (o su recreación artificial utilizando lenguas exóticas, como el chino) seguirá siendo un tema recurrente en la literatura utópica. El segundo episodio, el Diluvio Universal (Génesis, 6-7), abre nuevas vías especulativas sobre la conservación y transmisión de la lengua perfecta (recuérdese que sólo sobrevivieron al diluvio Noé y sus descendientes). Y generará una ingente literatura sobre la ubicación del Paraíso (ya sea terrestre - como lugar utópico donde habitaron Adán y Eva-, o celeste - como morada de las almas) en la que confluirán el imaginario lingüístico y el imaginario topográfico: los viajes fantásticos de Godwin (1638) y Cyrano (1657) al imperio de la Luna (un viejo topos paradisíaco), la fabulosa Terra incognita de Gabriel de Foigny (1676) o la isla de Laputa que describe Swift (1726) en Los viajes de Gulliver son ejemplos equiparables a los viajes interestelares de la moderna ciencia ficción. En estas narraciones los protagonistas descubren lenguas desconocidas, regulares y perfectas como la lengua originaria, que representan la realización de los sueños racionalistas aplicados al lenguaje humano.

El tercer episodio bíblico es el mito de la Torre de Babel y la Confussio linguarum (Génesis, 11: 1-9). Esta segunda caída de la arrogante especie humana en su empeño por alcanzar la divinidad provocó la pérdida de la unidad, dispersada y fragmentada en multitud de lenguas que acentúan aún más la añoranza 
del paraíso perdido: "Por ello se llamó Babel, porque allí confundió Yahvé la lengua de todos los habitantes de la tierra y los dispersó por toda su superficie" (Génesis 11: 9); y aunque elucida el misterio de la diversidad lingüística, pone de manifiesto sus terribles consecuencias ${ }^{1}$. Este mito será el germen de una fructífera literatura utópica que se inicia a finales del siglo XVIII cuyo objetivo, una vez desechados los dogmas religiosos que imperaron en los siglos anteriores acerca de la lengua originaria (única, en tanto don divino), culmina en la construcción de lenguas universales. Dichas lenguas serán proyectos a posteriori que no partirán ya de la naturaleza de las cosas, sino de las propias lenguas históricas (vivas o muertas). De ahí que la invención lingüística abandone la dimensión fantástica y diseñe proyectos científicos con lenguas artificiales prácticas como el Volapük o el Esperanto: lo imaginario, libre ya de las presiones religiosas y filosóficas, contribuye a la consolidación del nuevo género de la ciencia-ficción en el que los problemas lingüísticos (al menos en sus primeros años) pasan a ocupar un lugar secundario.

En el Nuevo Testamento el mito lingüístico se desarrolla en dos pasajes que suponen la redención mística del pecado de Babel: en el milagro de Pentecostés (Hechos de los apóstoles, 2: 1-8) y en la Primera Epístola de San Pablo a los Corintios (capítulos 13 y 14). Como se recordará, en el pasaje de Pentecostés los Apóstoles poseen el don de lenguas, de forma que, aún hablando en la suya propia, pueden ser comprendidos por cualquier interlocutor como si hablasen las lenguas particulares de cada uno de ellos, cumpliéndose así la promesa que les había hecho Jesucristo: "A los que creyeren les acompañarán estos prodigios: En mi nombre arrojarán los demonios, hablarán lenguas nuevas" (Marcos, 16, 17); otros creen que hablaban en arameo, aunque los oyentes lo entendían en su propia lengua; otros, finalmente, que los apóstoles hablaban una lengua extraña para ellos, entendida por todos, de forma que el milagro se verificaba al mismo tiempo en los apóstoles y en los oyentes. En la Primera Epístola de San Pablo la redención babélica tiene un acentuado matiz místico, pues aunque los fieles hablan lenguas diversas, pueden comunicarse directamente con Dios mediante la intervención del Espíritu Santo. En los textos recogidos del Nuevo Testamento se obra el milagro de la comprensión, si bien en el caso de Pentecostés se trata de una comunicación hombre a hombre, y en el pasaje de Corintio de la comunicación del hombre con la divinidad. Esta reconstrucción apostólica de la lingua adamica, esta suerte de "esperanto místico", surge de la necesidad de garantizar la comunicación humana mediante esquemas conceptuales compartidos que aseguren la unidad del lenguaje frente a la diversidad lingüística maldita desde Babel.

1 Babel es el nombre con el que los hebreos denominan a Babilonia o "Bab-ili", 'la puerta de Dios'. El texto del Génesis contiene también un juego de palabras con bab-el y bal-el ('confundir'). Este significado de "confusión" es el que vertebra el argumento de la película Babel (2006) dirigida por Alejandro González Iñárritu. 
Estos episodios bíblicos serán el germen de una fructífera literatura utópica en cuyos imaginarios topográficos se albergará la búsqueda de la lengua perfecta perdida o su reconstrucción artificial ${ }^{2}$.

\section{El sueño de la razón: los diseños filosóficos de lenguas artificiales}

El mito de la relación especular entre palabra y cosa atribuido a la lingua adami$c a$ en tanto que don divino inspiró a los filósofos del XVII para diseñar modelos lingüísticos en los que los signos representasen la "verdadera naturaleza de las cosas" y, por tanto, pudieran expresar el conocimiento y transmitirlo de manera unívoca, lejos de las imperfecciones, limitaciones y ambigüedades de las lenguas naturales. Estos diseños filosóficos, que no son sino el contrapunto científico al mito adámico de la relación especular entre palabra y cosa, se proponen como sistemas pseudolingüísticos (artificiales) a priori (construidos al margen de las lenguas naturales) que parten de una clasificación lógica previa de los conceptos y de sus derivados y combinaciones. Posteriormente, dichas clasificaciones se hacían corresponder con caracteres reales (signos ideográficos), de forma que estos indicaran de manera precisa el nombre de las cosas y su lugar en la naturaleza. Esta idea, enraizada en la tradición cabalística y lullística, verá la luz en la obra del francés M. Mersenne (Harmonie Universelle 1637), inspirada por el racionalista Descartes ${ }^{3}$ y basada en la posibilidad de una lengua universal musical y matemática en la que "le son des paroles n'a pas un tel rapport avec les choses naturelles, morales, \& sur-naturelles, que leur seule prononctiation nous puisse faire comprendre leur nature $[\ldots]$ il faut voir si l'art \& l'esprit des hommes peut inventer la meilleure langue de toutes les possibles" (1637: 317). La elaboración de proyectos artificiales comienza en Inglaterra años más tarde. Bajo la influencia del empirismo de F. Bacon se idean los proyectos de Lodwick (Common Writing 1647 y The Ground-Work for a New Perfect Language 1652), Cave Beck (Universal Character 1657), Dalgarno (Ars Signorum 1661) y Wilkins (Mercury 1641 y An Essay towards a Real Character

2 Algunos de estos relatos describen fantásticos viajes al imperio de la Luna, como los de Godwin (1638), Wilkins (1640) o Cyrano de Bergerac (1657), a islas exóticas (Swift 1726), o a la Fabulosa Terra incognita (las Tierras Australes) que describen Foigny (1676), Vairasse (1677), Tyssot de Patot (1710) o Casanova (1788), entre otros. En el siglo XIX, cuando ya no queda en la Tierra ningún lugar donde alojar la utopía, la ciencia ficción toma el relevo de los viajes imaginarios para habitar en Marte o en cualquier otra galaxia inexplorada. En estas narraciones los protagonistas descubren lenguas desconocidas, regulares y perfectas como la lengua originaria, que representan la realización de los sueños racionalistas aplicados a la lingüística. Dichas lenguas, en el caso de las utopías, vertebran un modelo de sociedad feliz en la que impera el orden y la igualdad, un proyecto de paraíso que servirá como revulsivo contra la injusta sociedad europea y sus lenguas llenas de irregularidades e incoherencias.

3 En la carta que Descartes escribió al padre Mersenne el 20 de noviembre de 1629, el filósofo señala que, al igual que existe un orden en la naturaleza, existe también una jerarquía entre las palabras de las lenguas; por tanto, si pudiera establecerse o reconstruirse, reflejaría el verdadero conocimiento, pues el lenguaje fue un don divino otorgado a Adán en el Paraíso. 
and a Philosophical Language 1668). En estos diseños la ordenación jerárquica del conocimiento se manifiesta en un complejo sistema gráfico de características reales más cercano a las pasigrafías, aunque pudiera ser leído en una lengua natural ${ }^{4}$. El método más común consistía en agrupar las palabras por clases semánticas (acordes con la clasificación previa de la realidad) asignando un único símbolo al conjunto; cada miembro del grupo se indicaba mediante un signo genérico principal más un añadido o marca distintiva. El resultado era un signo icónico que indicaba en su propia estructura el género y la especie a la que pertenecía el referente.

El sistema de Dalgarno (1661), respresentado en (1), por ejemplo,

(1) Dalgarno

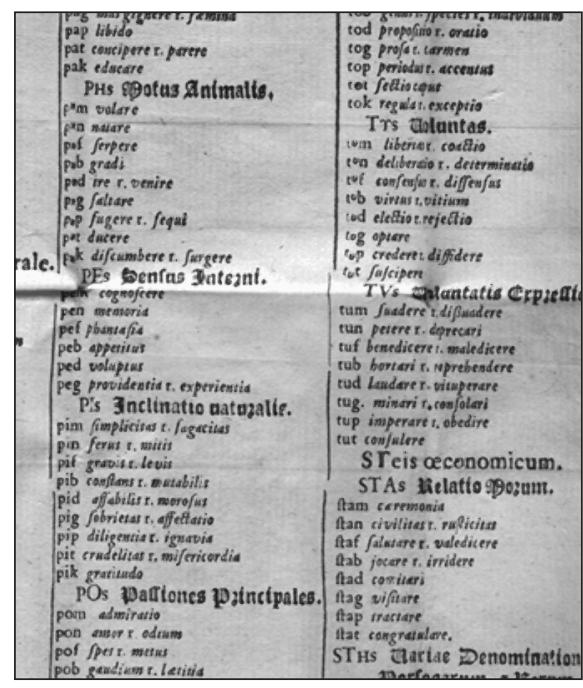

comprendía 17 clases supremas, designadas por 17 letras que se correspondían con la inicial de todas las palabras de la clase correspondiente. Estas clases se dividían en subclases, indicadas por la segunda letra. A su vez, las subclases comprendían varias palabras (sustantivos y verbos, pero no hay más elaboración sintáctica) que se distinguían por la última letra. El sistema de Wilkins (1668) dividía las ideas en 40 categorías caracterizadas por dos letras $(\mathrm{CV})$. Posteriormente, y mediante la adición de vocales y consonantes, subdividía las categorías en diferencias y en especies. La intención de los primeros inventores de características reales universales era proponer un medio de comunicación gráfico susceptible de ser leído en una lengua natural, por lo que Wilkins atribuyó a cada signo una sílaba (como se observa en la ilustración 2), aunque muy pronto fue notorio que se requería un enorme esfuerzo de aprendizaje y memorización.

4 Véanse los trabajos de Salmon (1972), Knowlson (1975), Slaughter (1982) y Asbach-Schnitker (1984). 
(2) Wilkins

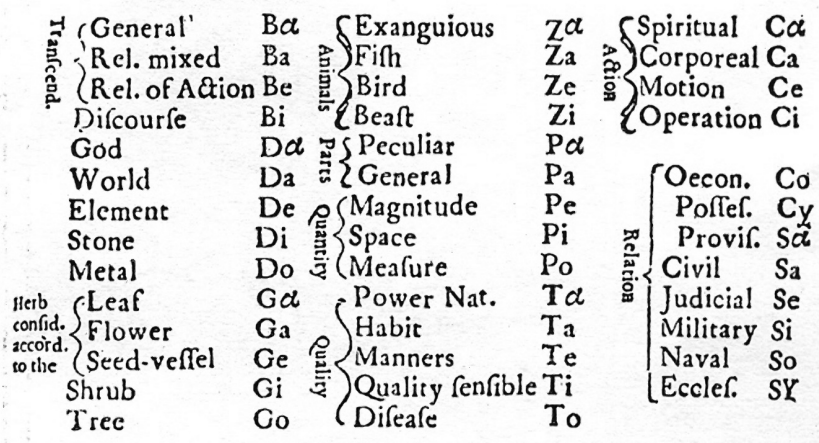

Este procedimiento, que continuará incluso en algunos proyectos filosóficos del XIX, pretendía reflejar la estructura de lo real, tal y como la percibían los hombres de ciencia de la época, pero en consonancia con las propiedades de la lingua adamica, según la creencia de los teólogos. En Alemania, la posibilidad de recrear la lingua adamica se ve impulsada por los escritos del místico Jacob Boehme (De signatura rerum 1651 y Mysterium magnum 1654); su influencia, además de la de los empiristas ingleses, es notable en las obras de Leibniz De arte combinatoria (1666) y New Essays (1705) cuyas características universales son operadores matemáticos (Couturat, 1901: 31); por último, hay que mencionar al checo Comenius (Via Lucis, Vestigata et Vestiganda 1668; aunque había sido escrita en 1661, poco después del Essay de Wilkins), cuyo interés por la construcción de una lengua universal era más filantrópico (terminar con los conflictos religiosos de la época) que científico ${ }^{5}$. Su visión utópica del mundo perfecto reside en la creación de un lenguaje nuevo en el que existan sólo las palabras necesarias para aludir a las cosas y en el que la sintaxis se limite a la unión de unas palabras con otras, "just as things are connected with each other in nature". Los sonidos, por su parte, han de representar lo más fielmente posible la naturaleza de las cosas por las que están. En tiempos pasados, dice Comenius, los hombres eran incapaces de percibir correctamente la naturaleza de las cosas y, por consiguiente, su lengua se fue alejando paulatinamente de la realidad.

5 Comenius no logró su objetivo, pero lo esencial de sus ideas se conserva en dos tratados manuscritos redactados en 1665 que han permanecido inéditos hasta hace unos años (Cervenka y V. T. Miskovska 1996). En el primero (Panglottia), citando a Dalgarno, esboza una serie de reglas para construir una lengua universal: "tantas cosas, tantas palabras; una cosa simple, una palabra simple; una cosa compuesta, una palabra compuesta" (1966, t. II: 183). En el segundo (Novae Harmonicae Linguae Tentamen Primum) discute los caracteres que podrían utilizarse, tales como líneas, combinaciones de puntos, figuras semicirculares y figuras redondas (1966, t. II: 191). Trata también la posibilidad de que los sonidos tengan una significación natural, idea que ya había sugerido Mersenne (1637) y puesto en práctica Sir Th. Urquhart en Logopandecteision (1653). 
Este alejamiento, que ocasionó la diversidad lingüística, también fue el origen de todas las disputas, controversias y guerras que han azotado a la humanidad. Sin embargo, Comenius, como todos los ilustrados de la época, cree en la posibilidad de recuperar la pureza bíblica perdida (Génesis, especialmente 2: 19-20 y 11: 1) con la construcción de una lengua nueva. Para abordar este proyecto propone dos métodos: el primero consiste en seleccionar los mejores recursos de las lenguas conocidas para construir una nueva (como ya había sugerido Bacon); el segundo es crear una lengua ex novo a partir de símbolos o "caracteres reales" cuya gramática se limitaría a un conjunto de reglas universales y a una serie de convenciones sobre la formación de palabras.

El deseo de claridad y exactitud en el discurso, unido a la esperanza por descubrir alguna lengua que hubiera escapado al castigo babélico, despertaron la curiosidad hacia aquellas lenguas que, o bien por su lejanía o bien por su singularidad, parecían acercarse a dichos ideales científicos y especulativos. La lengua china, de la que se tenían noticias vagas desde el siglo XIII, cumplía sobradamente estos requisitos. Las descripciones de H. Hugo (De prima scribendi origine 1617) y G. Vossius (De arte grammatica 1635) destacaron especialmente el carácter tonal del chino y contribuyeron también a difundir la falsa creencia de que los "caracteres reales" de esta lengua representaban cosas, de manera que cada símbolo "estaba por" un objeto determinado 6 , como muestra el comentario de A. Kircher (Oedipus Aegyptiacus 1670).

(3) Caracteres chinos

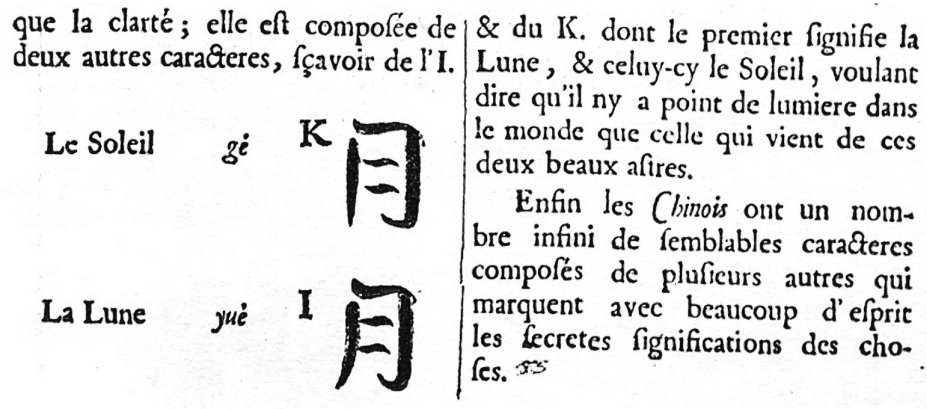

6 Pero si el chino fascinó a los filósofos no fue por su lengua, sino porque su sistema de escritura, común para todos sus dialectos, ofrecía la ilusión de una característica universal natural. Es interesante mencionar también que la imitación de los caracteres chinos contribuyó a la creación de los primeros sistemas estenográficos en Inglaterra, entre los que destacan los diseñados por Timothy Bright (Characterie, an art of short, swift and secret writing by characters 1588) y Peter Bales (Arte of Brachygraphie 1597). 
Este hecho (pese a su falsedad) abrió el camino de la construcción de lenguas artificiales.

Las utopías del XVII se nutrirán de todas estas influencias y aprovechando la fascinación que despertó la lengua china proyectarán lenguas musicales y simbólicas.

\section{Ficciones y utopías lingüísticas}

Aseguraba Nietzsche que tan sólo pueden definirse correctamente aquellas palabras que no tienen historia. Esta afirmación se hace más que evidente cuando tratamos de acercarnos a "utopía", un vocablo que ha ido cambiando y adaptándose a los tiempos en que le ha tocado desarrollarse. No en vano, la utopía supone un contrapunto crítico a la realidad presente y se articula indefectiblemente unido a ella.

La palabra "utopía" apareció en un pequeño volumen escrito por T. Moro en latín y publicado en Lovaina en 1516: De optimo rei publicae statu deque nova insula Utopia. Libellus vere aureus nec minus salutaris quam festivus clarissimi disertissimi viri Thomae Mori. En la edición de Lovaina (y en la posterior de Basilea, 1518) se incluye un pequeño texto escrito en una extraña lengua, la lengua utopiana, que se acompaña de una traducción al latín, más un alfabeto utopiano.

(4) Alfabeto utopiano

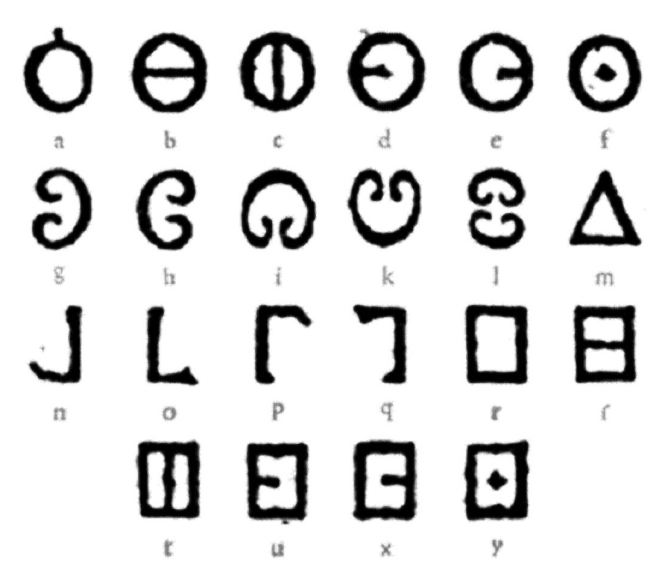

Sin embargo, el objetivo que persigue Moro no es encontrar el étimo de las palabras inventadas en la lengua utopiana, sino despertar su capacidad asociativa para recorrer, como en un viaje iniciático, el camino hacia la "verdad", hacia la verdadera esencia de las cosas. Recuérdese que la indagación etimológica se define como el saber "re-conocer" en una palabra aquella de la que procede; pero, además de re-conocer, es necesario también descubrir las formas constantes bajo 
la diversidad, idea acorde con la atmósfera esencialista (platónica y neoplatónica) del Renacimiento que envuelve a Moro. "Re-conocer" desde esta óptica es hacer perceptible aquello que estaba latente o que era ignorado (de hecho, "éthymon" significa 'verdadero', 'real'). Este esencialismo platónico marcará de manera notable las utopías lingüísticas de los siglos XVII y XVIII.

La publicación de la obra, más el extraño e incomprensible texto del apéndice, generó poco después un debate filológico sobre el significado de la palabra "utopía". Algunos humanistas se basaron en el étimo griego (ou- > 'no'; topos > 'lugar') para afirmar que "utopía" significaba 'no-lugar'; otros, en cambio, apoyándose en que en la edición de Basilea de 1518 aparece la palabra "eutopía" en una sextina adjunta al texto ("Por tanto, no Utopía, sino mejor es mi nombre Eutopía: país de la felicidad"), interpretaron que la partícula negativa ou- provenía de la modificación de eu-, 'bueno', 'justo', 'feliz'. De este modo, "utopía” asumiría el significado de 'región de la perfección y de la felicidad' y no el de 'lugar inexistente'. Aunque probablemente ninguna de las dos interpretaciones propuestas sea totalmente acertada, es interesante constatar que en la historia de la utopía que se abre tras la obra de Moro las dos posibilidades estarán siempre presentes favoreciendo un juego continuo de ambigüedad interpretativa que permitirá, además, la creación del término opuesto "distopía"; este neologismo designa un lugar inexistente (en consonancia con el primer significado privativo de "ou-") donde se asienta una sociedad negativa (en relación antonímica con el segundo significado de "eu-"). Y este es el dilema semántico que va a acompañar a los relatos utópicos, pues las utopías, en cuanto proyectos impracticables en lugares inexistentes y atemporales, no son sino el revés del espejo de las distopías, lugares inexistentes en los que tales proyectos se han llevado a cabo en algún momento del tiempo futuro ${ }^{7}$.

La isla de Moro cuenta con algunos antecedentes míticos: los griegos ya imaginaban ciudades ideales similares, si bien el modelo utópico por excelencia es La República platónica (IV a. C.), prototipo de la polis y de la sociedad perfecta. Otros mitos similares son la leyenda de La Atlántida, identificada con el mito del Mar de los Sargazos (tal como se recoge en el Timeo), Ultima Tule (descrita en la tragedia Medea, de Séneca) ${ }^{8}$, Brandán y la Isla de los Pájaros ${ }^{9}$, la Isla de

7 Las utopías ven el espacio aún no explorado como una esperanza, mientras que las distopías lo presentan como una amenaza; pero hay que esperar hasta principios del siglo XX para que aparezcan relatos claramente distópicos, como Nosotros, de Zamjátin (escrito entre 1920 y 1923, y publicado por primera vez en Inglaterra en 1924), Un mundo feliz de A. Huxley (1932) o 1984 de Orwell (1949), por citar algunos ejemplos significativos.

8 Tule es también el nombre que Colón dio a Islandia en 1477.

9 Desde el siglo VI, y durante toda la Edad Media, circularon varias las leyendas sobre un santo irlandés llamado Brandán (Brenainn, Brendan, en otras ocasiones), cuyos viajes le llevaron por islas encantadas y mares fantásticos. Una de estas islas utópicas recibe el nombre de Isla de San Balandrán o la Isla de los Pájaros. Posteriormente, Anatole France se inspira en esta leyenda para publicar $L a$ isla de los pingüinos (1908). 
las siete Ciudades ${ }^{10}$ o la deleitable Tierra de Cockaygne (para nosotros Jauja) ${ }^{11}$. Estos y otros mitos sobre islas y tierras vírgenes fascinaron a los humanistas y los estimularon a recuperar las viejas utopías y los relatos clásicos. El estudio de los mitos les llevará a creer en la existencia real de continentes desconocidos que aparecían mencionados en las obras de los clásicos y en la literatura de viajes de la época. Por ejemplo, Le Livre du chemin de lonc estude de Christine de Pisan, Pantagruel (1532) y Gargantúa (1534) de Rabelais ${ }^{12}$, la república imaginaria descrita en Reipublicae Christianopolis descriptio, de Andreae (1619), la Ciudad del Sol de Campanella (publicada en 1623, pero escrita en 1602), The Memoirs of Signor Gaudenzio da Lucca de Simon Berrington (1738), la Basiliade du célèbre Pilpai de Morelly (1753), La Découverte australe par un homme volant de Nicolás Restif de la Bretonne (1798), The Constitution of Spensonia, de Thomas Spence (1801) o News from Nowhere (1890) de Willian Morris, que hasta en su título recuerda el De Utopia de Moro.

\section{De la China a la Luna}

La nueva concepción cosmológica inspirada por la revolución galileo-copernicana había abierto una brecha en los dogmas de las Sagradas Escrituras basados hasta entonces en el sistema de Ptolomeo. La constitución del nuevo paradigma científico favorecerá, además, que resurja con fuerza la vieja tesis anterior a la era cristiana de la pluralidad de mundos habitados, lo que permitirá especular sobre nuevos lenguajes ${ }^{13}$.

\footnotetext{
10 Fundada por siete obispos españoles - o portugueses, según otras versiones - en su huida de España tras ser conquistada por los árabes. En cualquier caso, las dos versiones coinciden en el descubrimiento de una maravillosa isla sobre el Océano Atlántico en la que los obispos fundan siete ciudades perfectas. 11 Dicha tierra parece corresponderse con la región de los Hatun-Xauxas (habitantes del valle del Hatunmayo, hoy Valle del Mantaro), descubierta por Pizarro en 1533. Los cronistas que acompañaron a Pizarro, ante la majestuosidad y riqueza natural del Valle, inician sus crónicas y cartas con la frase "desde el País de Jauja". Es probable que Pizarro escribiera varias cartas a España en las que narraba estas maravillas; por lo tanto, parece lógico deducir que la imaginación de los españoles identificara Hatun-Xauxa con un país de fabulosas riquezas. Posteriormente, Petrus Nobilio publicó en Roma en 1560 un libro sobre esta leyenda. También el Romancero español del siglo XVII consideró que Jauja era el nombre de un país fabuloso y paradisíaco. Como país de Cucaña aparece en la narración inglesa The Land of Cockaygne (XIII), país que recoge el tópico del mundo al revés, pues los ríos fluyen con aceite, leche, miel y vino, los gansos vuelan ya asados, los monjes bailan con las monjas o todos los alimentos están "a pedir de boca". También hay un cuadro de Brueghel, con el título de País de Jauja (1567).

12 La princesa Babedec es hija del rey de los Amaurodes (nombre que coincide con el de los personajes utópicos de Moro) y la carta que Gargantúa escribe a su hijo es enviada desde Utopía.

13 Se planteó entonces una curiosa paradoja ideológica que los autores de la época resolverán con mejor o peor fortuna, pues había que conjugar el dogma cristiano sobre el "otro" mundo con la idea subversiva de los "otros mundos posibles". Por ejemplo, los lunarianos de Godwin son cristianos, porque se arrodillan al oír una imprecación religiosa y el mundo Lunar de Cyrano es un reflejo del paraíso.
} 
Entre el XVII y 1865 se escribirán numerosos libros que tratarán el tema de la pluralidad de mundos fabulando sobre viajes a la Luna ${ }^{14} \mathrm{o}$ a otros planetas del sistema solar.

Anticipando casi treinta años la fantasiosa hipótesis de $\mathrm{J}$. Webb ${ }^{15}$ que identificaba la lengua adámica con el chino, Francis Godwin escribió The Man in the Moon (publicada póstumamente en 1638). Es la primera obra de ficción que recoge el tema de la lengua filosófica musical y la fascinación de la época por la cultura y la lengua chinas noveladas en la lengua lunariana que, como el mandarín, es una lengua tonal. Además, en el relato de Godwin se muestra también la influencia de las teorías pitagóricas y platónicas que definen la música como la ciencia universal del mundo y la conciben como un reflejo de la armonía celeste.

El protagonista de la novela se llama Domingo Gonzales, un curioso personaje que existió realmente en la segunda mitad del siglo XII, vinculado a la escuela de traducción de Toledo. Sus habilidades comunicativas le permiten adiestrar a unos cisnes salvajes gracias a los cuales escapa del ataque de un navío inglés y llega a la región de la Luna. Cuando llega a su destino, Domingo se da cuenta de que las lenguas que conoce no son de ninguna utilidad para comprender la lengua de los lunarianos cuyo gran tamaño dependía, según constata el protagonista, de sus virtudes; pero solventa este inconveniente al pronunciar una imprecación religiosa ("Jesús y María") ante la cual los lunarianos caen postrados de rodillas; y de este hecho concluye el protagonista que los lunarianos son cristianos.

El curioso lenguaje musical de los lunarianos, al igual que el mandarín en China, es una lengua única para los diferentes reinos lunares. Este idioma universal, contrariamente a cuanto se pretenderá en los sucesivos idiomas utópicos, es una lengua costosa de aprender porque es un idioma tonal compuesto por sonidos extraños que no pueden ser reflejados gráficamente. La obra de Godwin sentó un importante precedente entre los literatos utópicos de épocas posteriores, pues se vieron obligados

\footnotetext{
14 Los viajes a la Luna han sido una constante en la historia de la humanidad, independientemente de que la intención fuera filosófica, satírica, científica o literaria. Quizá los precursores sean Aristófanes (su isla aérea Nefelokokygia es un satélite artificial) y Luciano de Samosata (en Historia verdadera describe un viaje a la Luna en barco). A partir del Renacimiento los escritores empiezan a enviar seres humanos a este satélite, como fabulan Tomás Moro (Utopía, 1516) y Johannes Kepler (Sommium astronomicum, 1634). En esta última obra se narra el azaroso viaje de Duracotus a la Luna conducido por demonios y su encuentro con los pripolvani y los subvolvani, laboriosos selenitas constructores de cráteres. Incluso John Wilkins, probablemente influido por el relato de Godwin, diseñó una máquina voladora en su obra The Discovery of a World in the Moone (1638). Desde luego el viajero más conocido, y en sentido estricto el creador de la ciencia ficción moderna, es Julio Verne (De la Tierra a la Luna 1865). Otro viajero notable es H. G. Wells, cuya novela Los primeros hombres en la Luna (1907) retoma el mundo subterráneo de Kepler porque concibe una Luna hueca. Véanse Nicolson (1960) y García Gual (2005).

15 An Historical Essay Endeavouring the Probability that Language of the Empire of China is the Primitive Language (1669).
} 
a describir las lenguas de las utopías que narraban. Por otra parte, la lengua musical también se convirtió en modelo para los filósofos que perseguían la "característica universal". De hecho, en el tratado de John Wilkins sobre comunicación cifrada (Mercury: on the Secret and Swift Messenger 1641), se discute la construcción de una lengua universal compuesta de notas musicales y no de sonidos articulados, citando explícitamente el lunariano de Godwin: "Los sabios deberían expresar las cosas y las ideas mediante notas musicales en vez de con palabras y letras, y así podrían otorgar a la humanidad un lenguaje universal" (Mercury, XVIII).

(5) Wilkins: Mercury (1641)

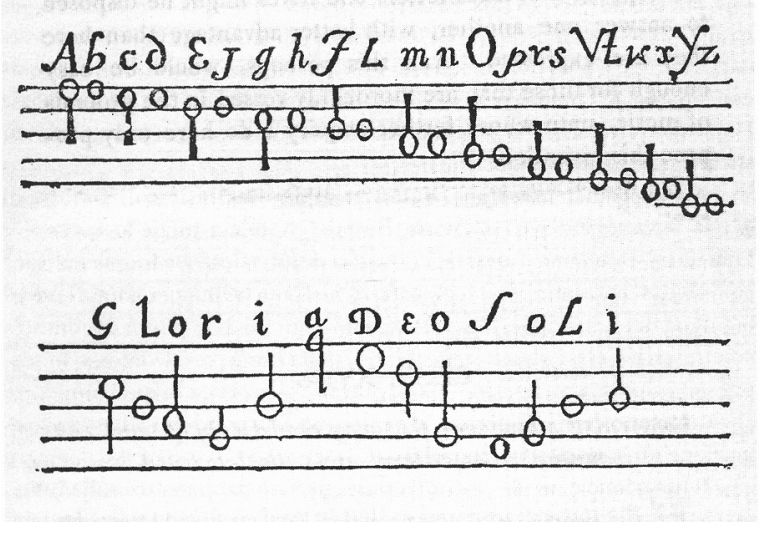

Si bien Wilkins optó finalmente por usar caracteres en lugar de notas musicales, ha de reconocerse la influencia notable del lenguaje de ficción de Godwin ${ }^{16}$.

Con un tono cómico e irónico, completamente distinto al de Godwin, Cyrano de Bergerac trata también la lengua musical lunar en Viaje a la Luna (1657) y en Historia cómica de los Estados e Imperios del Sol (1662). Al igual que la obra de Godwin, el mundo lunar de Cyrano muestra influencia de la cultura china, pues en el imperio de la Luna existen dos lenguajes: uno musical, armonioso y delicado, que habla la nobleza y otro vulgar y gestual, hablado por el pueblo. Pero mientras que para Godwin la música era una seria posibilidad para construir una lengua universal, en Cyrano es motivo de burla y caricatura (los diálogos son equiparables a un cuartero de música y el vulgo muestra un extraño baile de San Vito de gestos), una

16 En 1866 François Sudré creará la lengua musical universal Solresol. Dicho sistema utiliza los siete "signos" de la música (las siete "sílabas": do, re, mi, fa, sol, la si) tal y como se pronuncian en la lengua francesa. Como las posibilidades combinatorias de estas sílabas son limitadas, Sudre advierte de que sólo pueden expresarse ideas generales, por lo que una misma combinación debe servir para recubrir un campo significativo amplio. El nombre "Solresol", por ejemplo, designa los conceptos de 'lengua', 'idioma', 'dialecto' o 'jerga'. 
crítica indirecta a los diseños europeos basados en el modelo chino y un ataque a los proyectos de traducción del código lingüístico al musical como pretendió, entre otros, Mersenne en su Harmonie Universelle, 1636.

En el segundo viaje hacia la región del Sol Cyrano afronta el tema de la lengua adamica, argumento filosófico de la época. El interlocutor de sus conversaciones es el personaje llamado Mada (< Adam). Lo sorprendente de la lengua de Mada es que, aunque Cyrano no la había oído nunca, la comprende perfectamente porque, al ser la lengua primigenia, permite la intelección y Verdad inmediatas (de hecho, el personaje Mada aparece totalmente desnudo, como la Verdad). Sin embargo, el mito de la lingua adamica pierde en Cyrano su componente teológico-dogmático para convertirse en el ideal al que deben aspirar las lenguas filosóficas a priori en su deseo de obtener la realidad a través del auténtico conocimiento del nombre, como ya hiciera Adán cuando dio nombre a lo creado.

\section{La Terra incognita}

En la segunda mitad del siglo XVII la ubicación de las utopías se traslada desde los lejanos espacios interestelares hasta el hemisferio austral en cuyos mares está la fabulosa Terra Australis Incognita. Sus habitantes, los Antípodas, poseen una extraordinaria civilización política, social y lingüística. Esta creencia deriva del viejo mito medieval que, ante la necesidad de sostener el equilibrio entre los hemisferios terrestres, postulaba la existencia de un mundo del sur simétrico al conocido. La Iglesia no mantenía una opinión unánime: para algunos, era inconcebible la idea de un continente al sur cuyos habitantes caminaran cabeza abajo; para otros, la existencia de los antípodas ponía en duda la universalidad del verbo evangélico: si el cristianismo, por definición, estaba destinado a toda la humanidad, no podrían existir habitantes en las impenetrables zonas tórridas pues, si fuera así, se implicaría que no podían recibir la palabra de Dios. La Terra Australis se identificó con varios lugares, como África, Sudamérica o el polo Antártico, hasta que en 1770 Cook descubrió la tierra que hoy llamamos Australia.

Gabriel de Foigny publicó en 1676 La Terre Australe Connue, reimpreso en 1692 con el título Les avantures de Jacques Sadeur dans la découverte et le voiage de la Terre Australe. Como casi todos los viajes fantásticos de la época, el libro es la autobiografía del aventurero Sadeur quien, tras una serie de peripecias más o menos desafortunadas (piratas, naufragios, tierras y animales maravillosos), llega a una tierra desconocida casi semidesnudo tras una tempestad. Al igual que el personaje de Mada de Cyrano, tanto el protagonista Sadeur como los habitantes de la Terra Australis van desnudos y son hermafroditas, dos motivos importantes en la obra utópica de Foigny que enlazan, a su vez, con la tradición del mito preadámico: en primer lugar, la desnudez como símbolo de la Verdad simboliza el discurso perfecto y libre de ambigüedades: "hablar vestido equivale a declararse enemigo de la naturaleza y de la razón"; en segundo lugar, la androginia del pueblo austral sirve a Foigny para 
representar un ser libre de los impulsos de las pasiones y, por tanto, totalmente dedicado a la razón, connatural a su estructura biológica. Los hermafroditas no están sujetos a ningún impulso pasional porque no tienen la necesidad de buscar al "otro" para completarse, pues son en sí mismos seres perfectos. En consecuencia, la lengua que hablan ha de seguir necesariamente la vía de la lógica y de la razón.

El diseño de esta lengua muestra la influencia de las lenguas filosóficas a priori, pero sobre todo la influencia de la racionalidad cartesiana que había difundido la gramática de Port-Royal (Foigny defiende que las palabras son fruto del razonamiento, "suprema operación intelectiva", por eso sólo se habla cuando es absolutamente necesario). Como todas las lenguas a priori que pretenden ser un espejo de la razón, la lengua australiana posee una estructura muy simple que tiende a la aglutinación (como la lengua china), no existen declinaciones, artículos o morfemas de género, sólo hay una conjugación y tres tiempos verbales (pasado, presente y futuro). Las categorías gramaticales se reducen al nombre y al verbo y, en ocasiones, a una especie de aglutinación nombre-verbo. Dicha reducción (pues el objetivo es revelar la esencia de las cosas, como ya había sugerido Moro) hace que toda consonante o vocal sea el signo inseparable de una cualidad o de un objeto material; así, una palabra, en tanto reunión de letras, se corresponde exactamente con una combinación real, una química lingüística del mundo material o moral. Las palabras del vocabulario se forman con una combinación de las cinco vocales (que indican los cinco cuerpos simples: A-fuego, E-aire, O-sal, I-agua, U-tierra), más las 36 consonantes (que expresan la cualidad propia de las cosas: B-claro, C-caliente, F-seco, L-húmedo, S-blanco, N-negro, T-verde, P-dulce, R-amargo, M-deseable, etc.). Así, las estrellas se llaman AEB, porque están compuestas de fuego (A) y aire (E) más la cualidad que las distingue, la claridad (B). "Hombre" es UEL, pues tiene una parte aérea $(\mathrm{E})$, una parte terrestre (U) y una parte húmeda (L). En suma, como dice Foigny, "apenas se pronunciaba una palabra, ya se conocía la naturaleza de su significado, pues a toda emisión lingüística le corresponde una revelación inmediata de la naturaleza del mundo".

Junto a esta utopía hay que señalar también la Histoire des Sévarambes (1677) de Denis de Vairasse d'Allais, gramático contemporáneo de Foigny y, como este último, implicado en el movimiento racionalista en favor de la gramática universal. Vairasse conocía los viajes imaginarios de Godwin, Cyrano y Foigny y que los lenguajes creados para dichas utopías estaban basados en la lengua china. No obstante, en la construcción de su lengua surgen nuevas preocupaciones lingüísticas. La historia narra la estancia del capitán Siden (anagrama de Denis) en la fabulosa Terra Incognita Australis. La lengua de los Sevarambos, obra de su nomoteta Sevarias, es un método (una idea que posteriormente adaptará Condillac) $\mathrm{y}$, en este sentido, debe ser una creación convencional a posteriori, enriquecida con los conceptos de las lenguas que Sevarias (que resulta ser un "planificador lingüístico" avant la lettre) conoce; por tanto, $-\mathrm{y}$ este es el giro fundamental que 
se introduce en los diseños de lenguas utópicas - para diseñar una lengua perfecta basta con seleccionar lo mejor de cada lengua conocida y reunirlo en una lengua ideal. La idea del ensamblaje lingüístico que Vairasse propone, muy alejada ya del mito adámico, anticipa casi en dos siglos el proyecto de Esperanto de Zamenhof y los sistemas interlingüísticos afines. En su concepción también puede verse la exigencia - como ya propusieran Bacon, Leibniz o Humboldt - de reunir documentación sobre las diferentes lenguas para crear una gramática universal.

A pesar de ser un idioma convencional construido a posteriori no carece del ingrediente típico de las utopías de la época: la naturalidad. No obstante, Vairasse introduce una matización: si el fonosimbolismo es una muestra de la elegancia y decoro de los conceptos de la lengua ideal es porque dichos conceptos son necesariamente el reflejo de la educación espiritual e intelectiva del pueblo que la habla. De modo que la perfección de la lengua es la imagen sensible de la perfección ética. Es la primera vez que en las narraciones utópicas se sugiere el concepto de "genio" de un pueblo en relación con la perfección de la lengua.

\section{El revés del espejo}

El siglo XVIII revela una continuidad de fondo respecto a la concepción racionalista del lenguaje, pero empiezan a abrirse otras vías de reflexión. Mientras que en Francia se mantiene la orientación logicista en la invención de sistemas lingüísticos, en Inglaterra se asienta poco a poco la filosofía empirista, de modo que los presupuestos teológicos - tan fuertes en el XVII - entran en decadencia y con ellos comienzan a declinar también los proyectos de lenguas filosóficas y las narraciones utópicas sobre la lengua originaria. Los defensores más razonables del origen divino del lenguaje admiten que Dios ha otorgado al ser humano, no un lenguaje, sino la capacidad de crearlo; de ahí que las utopías que se diseñan en este siglo sean una caricatura de los mitos bíblicos y de las especulaciones filosóficas del siglo anterior.

La desconfianza hacia las palabras del lenguaje común (cuestión que planteó abiertamente F. Bacon y culminó en los proyectos de lenguas universales) y la obsesión por la relación palabra-cosa también están presentes en la sátira de Swift Gulliver's Travels (1726) ${ }^{17}$. Las alusiones al lenguaje y los juegos lingüísticos se muestran por doquier. Las primeras palabras en una lengua inventada aparecen en el viaje al país de Lilliput cuando Gulliver se despierta amarrado en la playa y oye cómo los pequeños seres gritan: "Hekinah degul" (p. 15), "Tolpo phonac" (p. 16), "Langro dehul san" (p. 16), "Borach mivola" (18), palabras que Swift no traduce y que han dado pie a todo tipo de especulaciones interpretativas: para algunos estudiosos (Clark, 1953) dichas expresiones son parte de un juego fónico

17 Cito por la edición española Viajes de Gulliver, Madrid, Espasa-Calpe, 2003. 
que imita el lenguaje infantil; otros establecen una relación de continuidad que parte del Tetrastichon de Moro, continúa con Rabelais y culmina en Swift (Pons, 1957). Como ya se sugirió al analizar el texto de Moro, en este tipo de juegos lingüísticos no es importante hallar una equivalencia fónica ni una interpretación satisfactoria, sino activar todos los procedimientos asociativos que el texto permita. Son más interesantes desde el punto de vista lingüístico las reflexiones contenidas en el Tercer Libro, donde se narra de manera irónica una especie de viaje extraterrestre en la tradición de Godwin y Cyrano hasta Laputa ${ }^{18}$ (una isla volante parodia de la Royal Society) y Balnibarbi (el continente "de abajo" dependiente y dominado por los gobernantes "de arriba"). Los habitantes de Laputa viven dedicados exclusivamente a la música y a las matemáticas; de hecho, su sistema lingüístico-cultural es un fiel reflejo de este interés. Sin embargo, Swift lo convierte en argumento paródico:

El rey, por lo que pude suponer, me hizo varias preguntas, y yo me dirigí a él en todos los idiomas que sabía. Cuando se vio que yo no podía entender ni hacerme entender, se me condujo, por orden suya, a una habitación de su palacio - sobresalía este príncipe entre todos sus predecesores por su hospitalidad a los extranjeros - , y se designaron dos criados para mi servicio. Me llevaron la comida, y cuatro personas de calidad, a quienes yo recordaba haber visto muy cerca del rey, me hicieron el honor de comer conmigo. Nos sirvieron dos entradas, de tres platos cada una. La primera fue un brazuelo de carnero cortado en triángulo equilátero, un trozo de vaca en romboide y un pudín en cicloide. La segunda, dos patos, empaquetados en forma de violín; salchichas y pudines imitando flautas y oboes, y un pecho de ternera en figura de arpa. Los criados nos cortaron el pan en conos, cilindros, paralelogramos y otras diferentes figuras matemáticas. (Cap. II: 129).

Tras describir minuciosamente los usos y costumbres de la Isla, Gulliver desciende al país de los Balnibarbi, en cuya Academia de Lagado se experimenta una reforma lingüística similar a la que vivía la Europa del siglo XVII. La "máquina generadora de lenguaje" que se describe (quizá una recreación del Ars magna de R. Llull y de la tabla combinatoria de Leibniz) es una dura crítica a la figura del gramático-filósofo racionalista empeñado en la búsqueda de una lengua perfecta capaz de contener el saber enciclopédico sobre el mundo.

18 "La palabra que yo traduzco por la isla volante o flotante es en el idioma original laputa, de la cual no he podido saber nunca la verdadera etimología. Lap, en el lenguaje antiguo fuera de uso, significa alto, y untuh, piloto; de donde dicen que, por corrupción, se deriva laputa, de lapuntuh. Pero yo no estoy conforme con esta derivación, que se me antoja un poco forzada. Me arriesgué a ofrecer a los eruditos de allá la suposición propia de que laputa era quasi lapouted: de lap, que significa realmente el jugueteo de los rayos del sol en el mar, y outed, ala. Lo cual, sin embargo, no quiero imponer, sino, simplemente, someterlo al juicioso lector". (Cap. II: 130). 
(6) Máquina del lenguaje de Gulliver

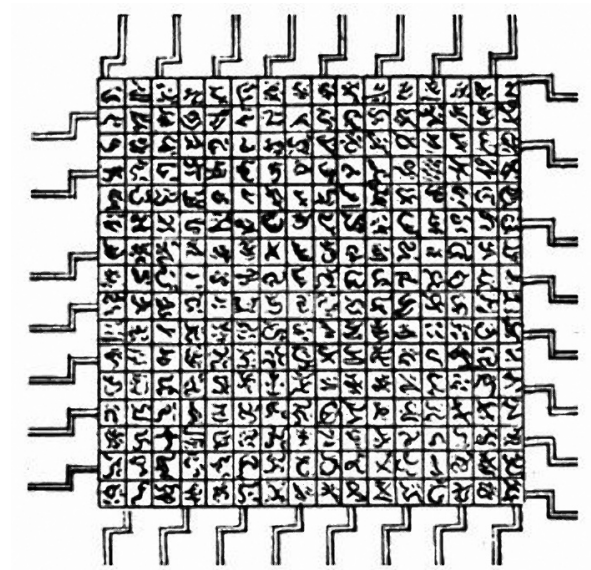

La ácida crítica al racionalismo lingüístico europeo y a la fantasía isomórfica de la lengua china (monosilábica, recuérdese) se hace más explícita en la descripción de los dos proyectos de la Escuela de Idiomas de Lagado, dedicada a simplificar las lenguas y a construir un lenguaje universal. El primer proyecto consistía en reducir los discursos a sustantivos monosílabos pues, en realidad, "todas las cosas imaginables son nombres y nada más que nombres" (Cap. V: 148).

Una vez nominalizado el discurso, esto es, "reificado", el segundo proyecto aniquila cualquier posibilidad lingüística de comunicación verbal en tanto que lleva al extremo satírico la búsqueda del isomorfismo absoluto palabra-cosa que tanto había preocupado a lingüistas y filósofos. Entablar un diálogo se reduce a la mera exposición de la pesada mercancía que se transporta en el saco:

[...] muchos de los más sabios y eruditos se adhirieron al nuevo método de expresarse por medio de cosas: lo que presenta como único inconveniente el de que cuando un hombre se ocupa en grandes y diversos asuntos se ve obligado, en proporción, a llevar a espaldas un gran talego de cosas, a menos que pueda pagar uno o dos robustos criados que le asistan. Yo he visto muchas veces a dos de estos sabios, casi abrumados por el peso de sus fardos, como van nuestros buhoneros, encontrarse en la calle, echar la carga a tierra, abrir los talegos y conversar durante una hora; y luego, meter los utensilios, ayudarse mutuamente a reasumir la carga y despedirse.

Mas para conversaciones cortas, un hombre puede llevar los necesarios utensilios en los bolsillos o debajo del brazo, y en su casa no puede faltarle lo que precise. Así, en la estancia donde se reúnen quienes practican este arte hay siempre a mano todas las cosas indispensables para alimentar este género artificial de conversaciones. 
Otra ventaja que se buscaba con este invento era que sirviese como idioma universal para todas las naciones civilizadas, cuyos muebles y útiles son, por regla general, iguales o tan parecidos, que puede comprenderse fácilmente cuál es su destino. Y de este modo los embajadores estarían en condiciones de tratar con príncipes o ministros de Estado extranjeros para quienes su lengua fuese por completo desconocida. (Cap. V: 148).

La ironía con que Swift se refiere a la concepción nominalista de la lengua ideal se acentúa especialmente cuando el autor recoge las opiniones del vulgo:

Y este invento se hubiese implantado, ciertamente, con gran comodidad y ahorro de salud para los individuos, de no haber las mujeres, en consorcio con el vulgo y los ignorantes, amenazado con alzarse en rebelión si no se les dejaba en libertad de hablar con la lengua, al modo de sus antepasados; que a tales extremos llegó siempre el vulgo en su enemiga por la ciencia. (Cap. V: 148).

Sin embargo, el sarcasmo hacia el vulgo ignorante que reniega del nominalismo encubre la reivindicación lingüística de Swift a favor de las lenguas vivas y cambiantes que recogen en su evolución la historia de los pueblos.

La búsqueda de la perfección a través de un lenguaje musical universal es el tema de la obra del danés Ludvig Holberg Nikolai Klimii iter subterraneum novam telluris theorum ac historiam quintae monarchiae, publicada en latín en 1741, casi un siglo después de las obras de Godwin y de Cyrano. El autor tiene el mérito de haber consolidado (Kircher, Swift y otros habían hablado de ello) el topos utópico de la terra cava. El protagonista, Klim, descubre que la tierra es cóncava y que esconde bajo la superficie un mundo más pequeño que el nuestro. Este descubrimiento es el inicio de una serie de viajes en los que recorrerá diferentes naciones y experimentará las más diversas aventuras.

En uno de estos viajes llega a la extraña Isla de la Semiminima (el término hace referencia a la notación y duración musicales) donde se ubica su utopía lingüísticamusical (argumento ya utilizado por Godwin y Cyrano), si bien la descripción de la lengua es una ácida caricatura en la línea iniciada por Swift. También es caricaturesco que exista un intérprete que conoce la lengua de los nativos, y que la comunicación se inicie haciendo sonar éste un enorme contrabajo ante cuyo sonido los habitantes responden con una melodía. El discurso continúa con un adagio, más una serie de sonidos discordantes, y termina con un delicado presto. Ante este final, los viajeros se muestran exultantes, pues significa que se ha llegado a un acuerdo sobre el precio de la mercancía que transporta el barco del protagonista Klim. Sólo entonces éste advierte que la música lenta al comienzo de la conversación era un preludio para el diálogo en el que se intercambian saludos y cumplimientos; si se oyen sonidos discordantes es porque se está discutiendo el precio de la mercancía y el acuerdo, si se alcanza, se marca con un presto. En este caso, la mercancía es 
la preciada pez griega, tan necesaria para los arcos de los contrabajos, instrumento esencial de su lengua. Se comprende ahora que la pena capital en esta isla sea privar a un nativo de su arco, pues tal castigo significa privarlo de la palabra. La descripción de los nativos roza también el ridículo pues, es una deformación evidente de la utopía lingüístico-musical, Holberg convierte a los hablantes de la Tierra cava en instrumentos de música:

[...] son seres de cuello largo, pequeña cabeza y cuerpo estrecho revestido de una corteza; sobre el ombligo se abre una concavidad con cuatro cuerdas. Se apoyaban sobre un solo pie y saltaban y se balanceaban constantemente. Podían pasar perfectamente por contrabajos si no tuvieran brazos y manos similares a los de los humanos, pero una de ellas se continuaba en un arco y la otra tocaba las cuerdas. Los niños de este país son violines, pero no reciben el arco hasta los tres años, mientras tanto asisten a la escuela para aprender a darle al instrumento una expresión clara.

A medida que se abandona la utopía de la lengua adámica, se consolida cada vez más la idea de la riqueza de la multiplicidad de lenguas (sin entender en esta diversidad ninguna maldición divina). Ya en 1746, Condillac (Essai sur l'origine des connaissances humaines) sostenía que todos los pueblos tenían un carácter específico que se correspondía con una lengua determinada. La noción de "genio de la lengua" como expresión del carácter del pueblo que la habla terminó por asentar definitivamente el principio de la diversidad y contribuyó al nacimiento de la metodología comparativa con el cambio de paradigma que ésta implica: hipótesis sobre el origen del lenguaje y de las lenguas, el concepto de diacronía y el papel que la sociedad y la cultura desempeñan en el cambio lingüístico, presupuestos que se habían apuntado en algunos de los relatos imaginarios anteriores.

La literatura utópica no es ajena a las nuevas ideas, como se muestra en la novela futurista L'An 2440, rêve s'il en fut jamais (1770-1771) de Louis-Sébastien Mercier, cuya acción se desarrolla en París. El protagonista es guiado en su viaje por un sabio anciano, personaje clásico de utopías anteriores y recreación del Virgilio dantesco. Mercier no describe la lengua (se da por supuesto que sigue siendo el francés), pero sí dedica un capítulo a discutir qué lenguas deben ser aprendidas en este mundo del futuro. El sabio anciano argumenta que las lenguas muertas no merecen ningún esfuerzo, pero tampoco el aprendizaje de las lenguas modernas amplía necesariamente el horizonte cognoscitivo del ser humano: si conocer muchas lenguas facilita la expresión de un mismo concepto bajo múltiples formas, sería mucho más productivo no aumentar el número de palabras aprendidas (formas), sino el de conceptos en una sola lengua. Sin embargo, es consciente de la dificultad de esta propuesta porque sería imposible evitar la rivalidad de las naciones y la preferencia por la lengua propia. La situación lingüística en este mundo del futuro permanece, pues, en una situación de plurilingüismo, aunque se señala que cada idioma tiene una 
característica especial para expresar determinadas disciplinas: así, el alemán debe ser la lengua de la química y de los naturalistas, el inglés la lengua de los poetas y de la historia, el italiano de las obras líricas, el español la lengua de los himnos y de las odas y el francés, la lengua de las novelas y de la política.

Al amparo de las teorías sobre la evolución del lenguaje propuestas por Vico (1744), Condillac (1746), Rousseau (1755) y Herder (1772) ${ }^{19}$, Nicolas Edme Restif (o Retif) publica en 1781 La découverte australe par un homme volant, ou le Dédale français. La novela trata de las aventuras de Victorin, inventor de una máquina voladora con la que explora un archipiélago de los mares del Sur (sólo dos años más tarde voló el primer globo aerostático). El viaje es una peregrinación en la historia evolutiva de la especie humana (hay hombres-toro, hombres-caballo, hombres-asno, hombres-rana, hombres-león) cuya primera lengua es onomatopéyica: los hombresleón rugen, los hombres-batracios croan, los hombres-toro mugen, etc.

Victorin (el Dédalo francés) se propone instruir a la comunidad en las leyes de la Razón y la Naturaleza; así, Victorin y su hijo seleccionan una pareja de cada especie (una clara alusión al mito del Arca de Noé) para educarlos fuera de su medio habitual con la pretensión de que propaguen las nuevas ideas una vez de regreso a su mundo. El personaje francés pretende igualmente propiciar la mezcla de todas las razas para llegar al grado más alto de evolución, porque supone que el futuro de la humanidad reside en el cruce de razas, por diversas que éstas sean, hasta llegar al hombre nuevo. Esta concepción revolucionaria rompe con la tradición de las utopías precedentes en las que el viajero era el instruido y no a la inversa. En la última isla, donde habitan los Megapatagonios, y cuyas semejanzas con Europa son muy claras, expone Restif sus ideas en materia filosófica, ideas que reflejan las utopías, un tanto platónicas, del momento: la defensa de la comunidad de bienes (recuérdese la propuesta de Moro), la designación del Estado como garante de la educación infantil o el reconocimiento a los sabios; pero todas estas propuestas se hacen en un mundo al revés. Curiosamente, los nombres de los habitantes, como el de la ciudad (Sirap) han de leerse a la inversa y el autor firma la obra escribiendo su nombre también al revés: Salocin-Emde-Fiter. El personaje de Restif atraviesa y rompe el espejo casi un siglo antes que Alicia.

\section{Al amparo de la historia}

A finales del XVIII poco o nada quedaba ya del viejo sueño utópico de la imago mundi. Pero el interés por la lengua filosófica no desaparece del todo, si bien con el nuevo siglo se produce un sugerente cambio de orientación hacia un terreno más pragmático y próximo al ser humano. Poco a poco se abren paso nuevas teorías ba-

19 Vico, Ciencia Nueva (1744); Condillac, Essai sur l'origine des connaissances humaines (1746); Rousseau, Discurso sobre el origen de la desigualdad (1755); Herder, Abhandlung über den Ursprung der Sprache (1772). 
sadas en la creación progresiva de las lenguas en las que, por primera vez, la acción del individuo es fundamental ${ }^{20}$. De esta forma, contra la tesis bíblicas sobre el don divino del lenguaje como espejo perfecto del mundo, cobran fuerza las propuestas lingüísticas que reclaman para el estudio de las lenguas el reflejo de la historia ${ }^{21}$.

Este cambio de paradigma afectará tanto a la creación de lenguas como al propio concepto de utopía: superadas las concepciones a priori y los dogmas religiosos sobre el lenguaje ${ }^{22}$, las nuevas lenguas universales serán construcciones a posteriori que no partirán ya de la naturaleza de las cosas (como pretendían las lenguas filosóficas), sino de las propias lenguas históricas; y serán lenguas híbridas construidas con materiales viejos y nuevos, con raíces primitivas y elementos modernos. El anhelo utópico de una lengua única para la especie humana se atisba como posible.

En el siglo XIX, especialmente entre 1880 y $1914^{23}$, se multiplican los diseños de lenguas artificiales (ancladas en las lenguas naturales) destinadas a la comunicación internacional, si bien este enorme esfuerzo de creación lingüística no se verá apenas reflejado en la ficción literaria. Uno de los últimos ejemplos de utopías lingüísticas es la lengua Vril-ya descrita en la novela de E.G. Bulwer Lytton The Coming Race (1871). Conforme a la tradición de la terra cava, la acción se desarrolla en un mundo subterráneo en el que se ha refugiado una raza superior de tipo céltico ${ }^{24}$ - los Vrilya- que posee poderes telepáticos e hipnóticos (p. 121) gracias al poder regenerador del fluido subterráneo "Vril", recreación simbólica del agua vivificadora bíblica:

It has been slowly developped in the course of generations, commencing in the early achievements and increasing with the continous exercise, of the vril power; therefore, in the course of one or two thousand years, such a nerve may possibly be engendered in those higher beings of your race, who devoted themselves to that paramount science through which is attained command over all the subtler forces of nature permeated by vril. (p. 143).

The type of face began to evince a marked change about a thousand years after the vril revolution, becoming then, with each generation, more serene, and in that serenity more terribly distinct from the faces of labouring and sinful men. (p. 147).

20 En 1771 Herder había ganado un concurso en la Academia de Berlín con un trabajo en el que defendía que el lenguaje es una pura y natural invención del ser humano.

21 Tal es el caso del grupo de pensadores franceses del XVIII denominado "les idéologues" (De Brosses, Gébelin, Desttut de Tracy). Contra las tesis sostenidas por los pensadores cristianos del XVII (Boehme, Kircher, Caramuel, entre otros), este grupo de ideólogos identifica la lengua primitiva con una lengua histórica evolucionada. En la misma línea, el inglés James Harris (Hermes or A philosophical inquiry concerning universal grammar, 1751) defendía la total arbitrariedad del lenguaje, en tanto símbolo construido por el ser humano y no mera imitación de la naturaleza.

22 El célebre segundo artículo de los Estatutos de la Sociedad Lingüística de París (1866) acordó prohibir cualquier estudio que concerniera al origen del lenguaje o a la búsqueda de la lengua universal.

23 Véanse los trabajos de Couturat y Leau (1903 y 1907).

24 La tesis que se argumenta (la evolución es perfección) recoge los supuestos del evolucionismo biológico darwiniano de El origen de las especies (1859). 
La lengua del relato comparte con las lenguas utópico-filosóficas precedentes la precisión, la regularidad, la economía de medios y la perfecta adecuación al pensamiento; sin embargo, en su diseño se siente la pujanza del nuevo paradigma lingüístico-comparativo del XIX, en especial, su interés por la reconstrucción histórica-evolutiva a partir del sánscrito: la lengua Vril-ya es un calco del modelo indoeuropeo y, de hecho, en la obra hay numerosas referencias a la teoría de los estadios (adaptada del modelo filosófico de Comte) y a las obras de Max Müller (estudioso del sánscrito, e ideológicamente cercano al autor). La lengua Vril-ya es una lengua perfecta pero, y esto es lo novedoso frente a la tradición utópica anterior, es perfecta porque ha evolucionado hasta alcanzar el tipo lingüístico flexivo. Su diseño es muy semejante a la estructura del sánscrito: es una lengua flexiva con cuatro casos cuyos sustantivos se forman con el sufijo sánscrito -ya; así, veed ("espíritu inmortal") > veed-ya ("inmortalidad"); vril ("potencia, virilidad") > vril-ya ("potencialidad", término que da nombre a la lengua) ${ }^{25}$. Otros sintagmas se componen de palabras inventadas más palabras existentes: como el término sánscrito nas- (atestiguado por Müller) que aparece en algunos compuestos neológicos: glek-nas ("degeneración universal por las guerras"), donde $g l$ - significa "universal", - ek "acontecimiento, lucha" y nas, "degeneración"; too-bodh ("filosofía"), donde bodh proviene claramente del sánscrito budh ("conocer") y too es un participio inventado que implica la acción de 'aprender con precaución'. Pah es una exclamación de desprecio para todo aquello insensato o falso, luego pah-bodh, literalmente "conocimiento fútil", designa la filosofía inútil y falsa dedicada a problemas metafísicos sin respuesta. La lengua tiene dos verbos auxiliares: $y a$ ("andar") y $z i$ ("estar" o "reposar"; en sánscrito la grafía de este último es si en lugar de zi). No faltan elementos simbólicos, como el sonido [Z], prefijo habitual de palabras que designan atracción o placer: zummer ("amante"), zutze ("amor"), zuzilia ("querido"), sonido frecuente en las palabras que una madre dirige a sus pequeños.

A partir de este diseño de ficción, la tipología lingüística pasa a convertirse en un tema utópico, pues el último estadio de la lengua coincide con el modelo indoeuropeo: la lengua Vril-ya, flexiva y perfecta, ha pasado (según la dinámica de las lenguas) por los dos estadios precedentes (aislante y aglutinante) ${ }^{26}$, requisito

$25 \mathrm{El}$ autor se apoya en los trabajos de Müller, quien había señalado construcciones semejantes en sánscrito: vid ("saber") > vid-ya ("sabiduría"); si ("reposar") > say-ya ("reposo").

26 El estadio aglutinante es muy negativo para Bulwer Lytton, pero no así el estadio aislante, pues era difícil despreciar la importancia de la civilización china. De este modo se mantiene un singular absurdo en la ideología del momento, y también en las utopías. La lengua china, prototipo de lengua aislante y considerada por ello simple, primitiva e infantil, despierta una gran admiración: parecía escapar de las leyes evolutivas, pues a pesar de su condición de aislante era el potente instrumento expresivo de un pueblo altamente civilizado. La contradicción teórica es evidente y el sustento de esta concepción no puede ser más que ideológico. Ciertamente, estaba también en el ambiente cultural de la época, pues las lenguas aglutinantes por excelencia - lenguas amerindias y africanas - pertenecían a pueblos colonizados por las potencias europeas. Las palabras de Baudry (1864: 73) son suficien- 
obligatorio de toda lengua para alcanzar su máxima expresión ${ }^{27}$. Desde este punto de vista, la evolución nunca es casual o fortuita, pues tiende a reunir - pasando por mejoras sucesivas - la perfección de todas las cosas; en suma, la labor del espíritu humano que ha conseguido reunir en una sola palabra expresión y concepto, dato empírico y forma a priori del acto del pensamiento.

Ahora bien, de una lengua tan rica, simple y eficaz cabría esperar una literatura fecunda; pero el autor señala que los géneros literarios no pueden coexistir con el feliz estado igualitario de los Vril-ya: las pasiones - origen de toda expresividad artística y literaria - son también el artefacto de todos los males e infelicidades del hombre, pues la ambición por distinguirse y afirmarse frente a los otros desencadena inestabilidades y turbulencias sociales. Por consiguiente, es el bienestar de la sociedad el que impone a los Vril-ya la anulación de las pasiones si se destinan a dichos fines artísticos. En esta tesis se ocultan las reflexiones del idealismo romántico inglés de Carlyle y Coleridge, entre otros, para quienes el héroe es el individuo cósmico-histórico de Hegel y la sociedad es aquella que favorece el igualitarismo, que repudia lo estético, que sofoca al individuo en favor del colectivo, que premia el materialismo contra el espíritu, que anula el futuro para anular los deseos. En Bulwer-Lytton, aunque tímidamente, comienza ya a gestarse la utopía negativa del siglo XX: a la historia le falta el futuro, a la lengua Vril-ya le falta la poesía, la posibilidad de producir. La lengua Vril-ya, como todas las lenguas utópicas, es una lengua inmóvil, estática (a pesar de haber pasado por una evolución), cerrada en su perfección y, por tanto, privada de los elementos renovadores y vitales de la creatividad. Todas las lenguas utópicas - y la Vril-ya no se distancia en este aspecto- son no-creativas y lógicas: no podemos imaginar

temente ilustradoras: “[...] la síntesis, obra de bárbaros, es manifiestamente menos apropiada que el análisis para traducir el pensamiento; [y ello] proviene directamente de la pobreza de sus ideas y de su frecuente repetición: la aglutinación se produce por la unión de las mismas palabras. Cuanto más bárbaro es un pueblo, más regular es su lenguaje [...] La civilización es la que destruye la bella armonía del lenguaje y la que violenta las palabras para que expresen cosas abstractas y complicadas, mientras que la barbarie, no expresando más que cosas simples, mantiene, por así decirlo, toda su frescura en las palabras transparentes. [...] Si el lenguaje es un espejo fiel del espíritu de los pueblos, el de los salvajes de América será sin duda muy rudimentario, pues su estado de nómadas cazadores es el más bajo de la escala" (la traducción es mía). No estamos muy lejos del "pensamiento salvaje" de LévyBruhl. (1927). Y resulta sorprendente la contradicción, pues la regularidad que Baudry reprocha a las lenguas primitivas no sólo fue el sueño de todos los proyectos utópicos anteriores, sino el objetivo de las modernas lenguas a posteriori que se crearán en el siglo XIX.

27 La fase aislante, representada por el chino, se considera la fase más antigua por su simplicidad estructural, rasgo que ya había sido atribuido a esta lengua en el imaginario utópico del siglo XVII. De esta forma, el chino, aunque no es la lengua madre primitiva, vuelve a ser el modelo, milagrosamente preservado, del estadio original por el que han pasado todas las lenguas antes de su evolución y progreso definitivos. Las modulaciones tonales se consideran igualmente una manifestación del carácter primitivo de las lenguas, según la vieja creencia de que en las primeras manifestaciones del lenguaje fueron musicales. 
términos o formas nuevas fuera del sistema y, si esto es así, no es posible hablar de cambio porque, si se produjera un cambio destinado a mejorar el sistema, habría que pensar que el estado de lengua, considerado perfecto, no lo era en absoluto. Por tanto, la perfección o es intangible o no es perfección. El transcurso del tiempo histórico, entendido como devenir de sucesos que se siguen y transforman, es imposible en el estado de perfección, el cual, privado de la dimensión temporal, nunca puede desarrollarse: sin futuro sólo se puede repetir hasta el infinito lo ya dicho. Paradójicamente la raza futura, al vértice de su camino evolutivo, si no puede tener futuro, no tiene ni historia ni lengua ni pensamiento ni nada. Está trazada la vía del utopismo negativo.

A finales del XIX, los trabajos de los neogramáticos y de la escuela sociológica francesa, entre otros, terminan por afianzar la idea de que las lenguas naturales son un producto de la cultura y están marcadas por el principio intangible de la arbitrariedad del signo, con lo que las teorías cratilistas, naturalistas e incluso mecanicistas terminan por recluirse en el lugar de lo fantástico. Lejos de ser inventarios de palabras que guardan una relación unívoca con segmentos definidos de la realidad ("cada cosa tiene un nombre"), las lenguas se conciben como sistemas de signos que analizan particularmente la realidad. Una lengua utópica es, en este sentido, una quimera. Aún así, el viejo sueño utópico sigue vivo. Desde finales del XX, y al amparo del enorme atractivo que tiene Internet, se han multiplicado los proyectos sobre utopías y uglosias, si bien el mito de la lengua única y perfecta (imago mundi) que inspiró los primeros diseños se ha fragmentado en esbozos ingenuos de desigual factura. Pero todas estas ficciones pseudocientíficas, convertidas por el poder de la palabra en relatos con los que alentar el sueño de lo imposible, son parte del sutil hilo que teje nuestra cultura occidental en la que las ideas sobre el lenguaje arrastran (o arrostran) viejos mitos para conformar otros nuevos.

Internet está demostrando en nuestros días el enorme atractivo que despierta el género utópico en su dimensión virtual. El incremento de lenguas artificiales que se observa en nuestra época es un acontecimiento insólito que se remonta a los proyectos de lenguas filosóficas del XVII, a las lenguas utópicas a posteriori, como el Esperanto o el Volapük o incluso a las lenguas privadas, como el Klingon o el Qenya, que han generado formas de vida y cultura de gran éxito. Pero el caso de Internet es diferente: reúne en un espacio nuevo (tan utópico en su concepción como lo fue la isla de Moro) a multitud de aficionados y de expertos lingüistas (glotomaníacos, como opina Eco; lunáticos del lenguaje, según Yaguello) fascinados por la creación de nuevas lenguas. Aunque en Investigaciones filosóficas (1988) Wittgenstein niega la condición lingüística del lenguaje privado por cuanto que su solipsismo excluye la posibilidad de tener audiencia (esta crítica al solipsismo parece dirigida a los "inventores de lenguas"), Internet está demostrando la viabilidad de los lenguajes privados en el sentido wittgensteiniano; de 
hecho, algunos "conlangers" ('constructores de lenguas') han diseñado modelos en los que las palabras privadas tienen un significado público y son discutidas y evaluadas en foros y listas. Las críticas no deben obviar tampoco que el enorme poder de la Red ha hecho posible el viejo sueño de los utópicos; y muchas de las deficiencias lingüísticas que los lingüistas actuales detectan en los nuevos proyectos fueron el ideal que perseguían las lenguas utópicas del XVII: la simplicidad, la reduplicación silábica o la simetría con el mundo constituyeron el punto de partida de aquellas primeras utopías que, marcadas por la fuerza de los mitos o por la filosofía de la época, perseguían la lengua única y perfecta. En la Red, sin embargo, el mito de la lengua única se ha fragmentado en miles de proyectos. En líneas generales, y salvo excepciones, los creadores de lenguas intentan que sus modelos sean diferentes de los paradigmas lingüísticos europeos, por lo que suelen acudir a lenguas de origen incierto, como el tagalo, el vasco o el azteca, en lugar de partir de las lenguas de origen indoeuropeo.

La actividad lingüística en la Red es de tal magnitud que incluso se proponen ejercicios de traducción de textos emblemáticos (el más utilizado es el episodio bíblico de la Torre de Babel). Es cierto que las lenguas inventadas de la Red difieren radicalmente de las lenguas naturales porque no son proyectos destinados a una audiencia y no permiten pensar o hablar con fluidez, excepto tras un laborioso proceso de traducción. Estos inconvenientes, que frenaron los proyectos lingüísticos en los siglos XVII y XVIII, no parecen afectar a la expansión de este fenómeno en la actualidad. Lejos de convertirse en un pasatiempo de lunáticos o románticos, muchas de estas lenguas inventadas se utilizan con fines didácticos. Jeff Henning, autor de la página Langmaker ofrece la posibilidad de "entrar" en un Laboratorio y fabricar una lengua propia, una oportunidad magnífica para explicar y comprender los mecanismos de la tipología lingüística. Por esta razón, y a pesar de las incertidumbres, cuando Eco (1994: 28) afirma que la historia de la lengua universal es "la historia de una utopía y de una serie de fracasos", no puede negar su "estela de consecuencias benéficas" en ámbitos tan dispares como las taxonomías de las ciencias naturales, la lingüística comparada, los lenguajes formales, los proyectos de inteligencia artificial y las ciencias cognitivas. Y es innegable que el afán por construir una lengua universal ha promovido una profunda reflexión sobre los problemas derivados de la comunicación internacional, la forma en que se organiza el pensamiento, los límites de las lenguas humanas y la ductilidad del lenguaje como sistema de comunicación. Nos encontramos, pues, frente a un fenómeno que merece más atención de la que ha recibido, porque conjuga el fecundo interés por la invención linguiística con las nuevas tecnologías. Un imaginario, en suma, que encuentra su lugar idóneo en la cada vez más frecuentada Red informática. Podíamos pensar que la tecnología ha hecho realidad el concepto utópico de lugar virtual, un lugar hecho de palabras y no de espacio, el viejo sueño de la utopía histórica. 


\section{Referencias bibliográficas}

AA.VV. (1979): Le mythe de la langue universelle. Número monográfico de Critique 387388, août-septembre.

Asbach-Schnitker, B. (1984): "Introduction”. En Wilkins, J.: Mercury. Amsterdam, John Benjamins, págs. IX-CIX.

Bacon, F. (1605): On the Dignity and Advancement of Learning. New York, 1986.

Baudry, F. (1864): De la Science du Langage. Paris.

Bulwer-Lytton, E. (1886): The Coming Race. London, Routledge, 1981.

Calero Vaquera, M. ${ }^{a}$ L. (2005): "Las lenguas artificiales". En Reflexiones sobre el lenguaje en la literatura. Universidad de Córdoba. Manual Didáctico e Interactivo de Lingüística General. [CD-ROM].

Casanova, I. (1788): Icosameron, Or, the Story of Edward and Elizabeth: Who Spent EightyOne Years in the Land of the Megamicres, Original Inhabitants of Proto. New York, Jena Press, 1986.

Cervenka, J. y V. T. Miskovska (1996): De rerum humanarum emendatione consultatio catholica. Prague, Academia Scientiarum Bohemoslovaca.

Couturat, L. y L. Léau (1903): Histoire de la langue universelle. Paris, Hachette.

Couturat, L. y L. Léau (1907): Les Nouvelles Langues internationals. Paris, Hachette.

Cyrano de Bergerac, H. S. (1657 y 1662): Viajes a la Luna. Historia cómica de los Estados e Imperios del Sol. Madrid, Adiax, Colección Fénix, 1982.

Descartes, R. (1629): Oeuvres, Correspondance I, edición crítica de J. Vrin. Paris, 1974, págs. 76-82.

Eco, U. (1993): La búsqueda de la lengua perfecta. Barcelona, Grijalbo Mondadori, 1994.

Foigny, G. (1676): La Terre Australe, Génova. (A New Discovery of Terra Incognita Australis, or the Southern World, by James Sadeur a French Man who being Cast there by Shipwrack, lived 35 years in that Country, and gives a particular Description of the Manners, Customs, Religion, Law, Studies, and Wars, of these Southern People; and some animals peculiar to that place: with several other Rarities. These Memoirs were thought so curious, that they were kept Secret in the Closet of a Late Great Minister of State, and never published until now since his Death). London, 1693.

García Gual, C. (2005): Viajes a la Luna. Madrid, ELR Ediciones.

Godwin, F. (1638): The Man in the Moon. Traducción española: Aventuras de Domingo González en su extraño viaje al mundo Lunar. Madrid, Victoriano Suárez, 1958.

Harris, J. (1751): Hermes or A philosophical inquiry concerning universal grammar. London, 1765.

Holberg, L. (1741): Nikolai Klimii iter subterraneum novam telluris theorum ac historiam quintae monarchiae adhunc nobis incognitae. Lipsia.

Hugo, H. (1617): De Prima Scribendi Origine et Universa Rei Literariae. Antverpiae ex Officina Platiniana: Apud Balthasarem et Johannem Morei, MDCXVII.

Kircher, A. (1670): Oedipus Aegyptiacus. Roma.

Knowlson, J. (1975): Universal language schemas in England and France, 1660-1890. University Toronto Press.

Lévy-Bruhl, L. (1927): Alma primitiva. Madrid, Sarpe, 1985.

Mercier, L. S. (1770-1771): L'An 2440, rêve s'il en fut jamais. Paris. 
Mersenne, M. (1637): Harmonie Universelle contenent la Théorie et la Practique de la Musique. Paris, CNRS, 1963.

Moro, Th. (1516): Libellus vere aureus nec minus salutaris quam festivus de optimo reip[ublicae] statu, deq[ue] noua Insula Vtopia. Louvain, Arte Theodorice Martini.

Nicolson, M. H. (1960): Voyages to the Moon. New York, Macmillan Company.

Pellerey, R. (1992a): "L'Ars signorum de Dalgarno: Une langue philosophique”. En Pellerey, R. (ed.): Le lingue perfette nel secolo dell'utopia. Roma-Bari, Laterza, págs. 147-162.

Pellerey, R. (1992b): Le lingue perfette. Número monográfico triple de Versus. Quaderni di studi semiotici. 61, 62 y 63.

Rabelais (1534): Gargantúa y Pantagruel. Madrid, M. Aguilar, 1923.

Restif de la Bretonne, N. E. (1781): La découverte australe par un homme volant, ou le Dédale français. Paris.

Salmon, V. (1972): The Works of Francis Lodwick in the Intellectual Context of the Seventeenth Century. London, Longmans.

Salmon, V. (1992): "Caractéristiques et langues universelles”. En Auroux, S. (dir.): Histoire des idées linguistiques. Tome 2: Le développement de la grammaire occidentale. Liège, P. Mardaga, págs. 407-423.

Salmon, V. (1996): "Language planning in seventeenth-century England. Its context and aims". En Bazell, C. et alii (eds.): In memory of J.R. Firth. London, Longman, págs. 370-397.

Slaughter, M. (1982): Universal languages and scientific taxonomy in the seventeenth century. Cambridge, Cambridge University Press.

Stillman, R. E. (1995): New Philosophy \& Universal Languages in Seventeenth Century England. Bucknell University Press.

Swift, J. (1726): Los viajes de Gulliver. Madrid, Espasa-Calpe, 2003.

Tyssot de Patot, S. (1710): Voyages et adventures de Jacques Massé. Genève, Slatkine Reprints, 1979.

Vairasse d'Allais, D. (1677-1678): Histoire des Sevarambes, peuples qui habitent une Partie du troisième communêment appelé LA TERRE AUSTRALE. Contenant une Relation du Gouvernement, des Moeurs, de la Religion, \& du Langage de cette Nation, innonnuë jusqu'à present aux Peuples de l'Europe. Amsterdam, Estienne Roger, 1702, 2 tomes; première éd. Paris, Michalet, 1677-1678.

Vossius, G. J. (1635): De Arte Grammatica Libri Septem. Amsterdami, Apud Guilielmum Blaeu, 1635.

Wilkins, J. (1640): The Discovery of a New World or a Discourse Tending to Prove that is Probable that There May Be a Habitable World on the Moon. London.

Wilkins, J. (1641): Mercury or the Secret and Swift Messenger. London.

Wilkins, J. (1668): An Essay Towards a Real Character and a Philosophical Language. Menston, The Scholar Press, 1968 (edición facsímil).

Wittgenstein, L. (1953): Investigaciones filosóficas. Barcelona, Crítica, 1988.

Yaguello, M. (1985): La Linguistique fantastique. Paris, Éditions Denoël. 
